\title{
Uma Arquitetura Pedagógica Para Aprendizagem Baseada na Fabricação Digital
}

\author{
Karen Selbach Borges ${ }^{1}$, Crediné Silva de Menezes ${ }^{2}$ \\ Instituto Federal de Educação, Ciência e Tecnologia do Rio Grande do Sul, \\ Campus Porto Alegre (IFRS) \\ Rua Cel. Vicente, 281 - Centro Histórico - Porto Alegre - RS - Brazil \\ Universidade Federal do Rio Grande do Sul (UFRGS) \\ Av. Paulo Gama s/n - Prédio 12201 - Porto Alegre - RS - Brazil \\ karen.borges@poa.ifrs.edu.br, credine@gmail.com
}

\begin{abstract}
In educational makerspaces, tools as laser cutters and $3 D$ printers, become importante resources for the learning process because they can give form and functionality to abstract ideas. It's necessary to highlight that the reflective process is so important as the fabrication activity, because it will improve subjects' awareness. Considering that, we propose an Educational Framework based on Jean Piaget's epistemology, wich explore digital fabrication tools to support knowledge construction.
\end{abstract}

Resumo. Em makerspaces educacionais ferramentas como cortadora laser e impressora $3 D$ tornam-se aliadas da aprendizagem uma vez que permitem tornar concreto aquilo que antes só existia no plano das ideias e das possibilidades. É preciso, porém, que a atividade na qual os sujeitos se engajem tenha por objetivo não apenas a construção do artefato, mas também a reflexão sobre as atividades e seus resultados. Dessa forma, propomos uma Arquitetura Pedagógica, sustentada pela epistemologia de Jean Piaget, que utiliza a fabricação digital como suporte tecnológico para a construção do conhecimento.

\section{Introdução}

Existem vários métodos ativos de aprendizagem, e recentemente tem-se destacado a "Aprendizagem Mão Na Massa" (PORVIR, 2018), que tem como princípio o aprender pelo fazer e está fundamentada no construcionismo de Papert. Esse observou que o desenvolvimento dos mecanismos cognitivos é privilegiado em situações em que o sujeito esteja conscientemente envolvido na construção de alguma coisa utilizando, para tanto, "objetos para pensar com", tais como os computadores. Com a evolução tecnológica as alternativas de "objetos para pensar com" se expandiram e passaram a contar com kits de robótica, kits de automação (compostos por sensores, atuadores e controladores, como os Arduínos) e ferramentas de prototipação e fabricação digital, tais como fresadora, cortadora laser, plotter de recorte e impressora 3D. Todos esses equipamentos são controlados por comando numérico (CNC - Computerized Numeric Control Machines), ou seja, são operados a partir de arquivos de computador. Inicialmente esses equipamentos eram encontrados apenas em laboratórios de engenharia, hoje configuram-se como ferramentas para a educação das áreas de Ciềncias, Tecnologias, Engenharia e Matemática (STEM - Science, Technology, Engineering, Mathematic) e estão se tornando mais acessíveis graças à criação de laboratórios de criatividade, prototipação e inovação conhecidos como makerspaces.

Os makerspaces constituem importantes ambientes de aprendizagem. A aparente desorganização desses espaços, sempre cheios de ferramentas, materiais alternativos para fabricação, protótipos em teste e elementos criativos, tornam os makerspaces um 
VII Congresso Brasileiro de Informática na Educação (CBIE 2018)

Anais do XXIX Simpósio Brasileiro de Informática na Educação (SBIE 2018)

espaço constante de desequilibração. Como diz Menezes et. al. (2006) "ao contrário do que possa parecer, quanto mais complexo o ambiente, no sentido de disponibilizar uma maior interação, maior será a possibilidade de aprendizagem". Os sujeitos, quando expostos à esse tipo de ambiente, envolvidos em projetos interdisciplinares, muitas vezes com áreas que não são de seu domínio, têm grandes chances de desenvolverem novos esquemas cognitivos ou, no mínimo, a melhorarem o seus esquemas conceituais pelo processo de auto-regulação.

É preciso, porém, que a atividade na qual os sujeitos se engajem tenha por objetivo não apenas a construção de um artefato, mas também a reflexão sobre o processo. Isso irá contribuir para uma tomada de consciência e, consequentemente, a "transformação dos esquemas de ação em noções e operações". (PIAGET, 1978 p. 10), que caracteriza o desenvolvimento cognitivo humano. Assim, se faz necessária uma prática pedagógica capaz de dar direcionamento às atividades com um suporte teórico adequado à construção do conhecimento. Encontramos nas Arquiteturas Pedagógicas (APs) uma possibilidade para isso. As APs são propostas de trabalho estruturantes, maleáveis e adaptáveis a diferentes enfoques temáticos, que combinam epistemologia e concepção pedagógica com o aparato tecnológico. "A tecnologia não é entendida apenas como um suporte para as ações dos sujeitos, mas sim como elemento que também constitui as novas relações e formas de pensar." (MENEZES et.al, 2013 p. 6)

A partir dessa concepção de prática pedagógica, foi elaborada uma arquitetura pedagógica para aprendizagem baseada na fabricação digital denominada APAME Arquitetura Pedagógica Para Aprendizagem em Makerspaces Educacionais, a qual será detalhada na seção 3 e exemplificada na seção 5 desse artigo. Antes disso, na seção 2, será analidado o trabalho de Jean Piaget em relação ao desenvolvimento cognitivo, especialmente no que diz respeito aos níveis operatórios. Na seção 4 será analisada a relação da APAME com o uso do pensamento formal. Por fỉm, na seção 6 serão apresentadas as conclusões, seguidas das referências às obras que embasaram a elaboração desse artigo.

\section{Os Estágios Operatórios de Desenvolvimento}

Para Piaget (1995) uma operação "é uma ação interiorizada que modifica o objeto do conhecimento ... Mas, além disso, é uma ação reversível; isto é, que ocorre nos dois sentidos, por exemplo, juntar ou separar. Assim, é um tipo particular de ação que constrói estruturas lógicas" (p. 2). Quando o sujeito necessita do apoio de objetos concretos para desenvolver raciocínios ele é dito Operatório Concreto, mas quando o raciocínio passa a ocorrer baseado em hipóteses, então o sujeito é considerado Operatório Formal.

A principal característica do estágio Operatório Formal é o fato de que o sujeito adquire a capacidade de separar o conteúdo da forma e, através da abstração, retirar da realidade as informações necessárias para determinar possibilidades (hipóteses) e deduzir delas as suas consequências. Nesse estágio as abstrações reflexionantes passam a ocorrer com mais frequência do que nos estágios anteriores, sendo que a abstração refletida, um subtipo de abstração reflexionante, é a responsável pela tomada de consciência do processo de reflexão, quando o sujeito encontra "as razões da conexão, até então, simplesmente constatadas" (PIAGET, 1995b, p. 275).

O pensamento formal é essencialmente hipotético-dedutivo e apoia-se nas operações proposicionais e combinatórias. Além dessas, os sujeitos formais são capazes de realizar operações sobre operações, também chamadas de operações de segunda ordem, tais como: probabilidade, correlação, compensação e proporcionalidade. Ao 
VII Congresso Brasileiro de Informática na Educação (CBIE 2018)

Anais do XXIX Simpósio Brasileiro de Informática na Educação (SBIE 2018)

atingirem o nível mais elevado do pensamento formal, os sujeitos tornam-se capazes de realizar as operações de Identidade, Inversão, Reciprocidade e Correlação (INRC).

\section{Arquitetura Pedagógica para Aprendizagem em Makerspaces Educacionais}

A Arquitetura Pedagógica Para Aprendizagem em Makerspaces Educacionais (APAME), apresentada pela Figura 1, propõe uma organização de trabalho, cujas atividades envolvem o uso de tecnologias digitais e são amparadas pela epistemologia de Jean Piaget (BORGES; MENEZES; FAGUNDES, 2017). Cabe destacar que, no caso da APAME, os projetos têm como objetivo a construção de um artefato físico a partir da articulação de conhecimentos e habilidades nas áreas de design, engenharia e computação.

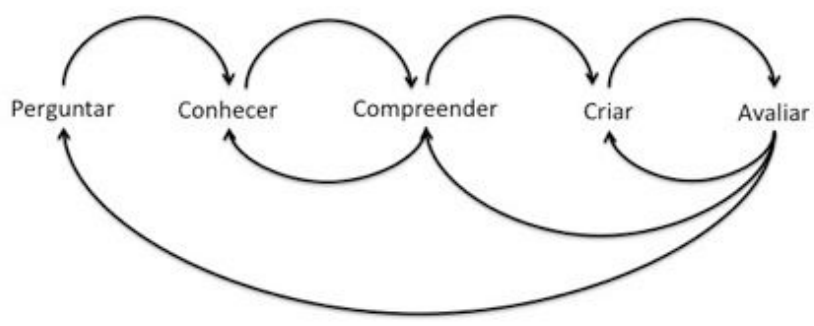

Figura 1 - Momentos da APAME

Como mostra a Figura 1, a APAME possui cinco momentos que se sucedem, mas que permitem também os retrocessos inerentes aos fazer e compreender. Cada um desses momentos tem objetivos bem específicos, a saber:

1. Perguntar: essa etapa visa levar o aluno a identificar as oportunidades de pesquisa e formular as questões que irão orientar o desenvolvimento do projeto.

2. Conhecer: momento em que o sujeito obtém informações mais aprofundadas sobre os elementos (técnicos, humanos e éticos) que compõem o problema. Pode envolver atividades como desmontar um equipamento, pesquisar soluções já existentes, conhecer as tecnologias que poderão ajudar na solução, conhecer as leis relacionadas ao problema, entre outros.

3. Compreender: momento que está intimamente ligado ao conhecer, pois quanto mais se conhece o objeto de pesquisa, melhor se compreende o problema e a solução a qual se deseja chegar. Nesta etapa, alguns conhecimentos tidos como certos podem se mostrar provisório. Nesse caso, é possível que se faça necessário buscar outros conhecimentos que irão ajuda a compreender 0 problema.

4. Criar: corresponde à etapa de fabricação, de correções e ajustes do projeto. $\mathrm{O}$ sujeito torna concreto aquilo que era abstrato. Por causa disso, a avaliação deve ser constante, sendo realizada toda vez que uma parte do projeto toma forma.

5. Avaliar: é quando se coloca em uso aquilo que foi criado, sujeitando o objeto a inspeções, testes e comparações. Disso pode resultar a necessidade de correções ou modificações do projeto e até mesmo a necessidade de se compreender melhor os elementos do problema e da solução projetada. Pode 
VII Congresso Brasileiro de Informática na Educação (CBIE 2018)

Anais do XXIX Simpósio Brasileiro de Informática na Educação (SBIE 2018)

ainda, ser o início de um novo ciclo de perguntar, conhecer, compreender, criar e testar.

\subsection{Suporte Telemático}

A documentação do desenvolvimento dos projetos é parte fundamental dessa AP. Seja na forma de portfólio de projetos ou diário de bordo, o aluno registra a evolução do produto, os processos criativos, de fabricação e de aprendizagem, e os conhecimentos adquiridos ao longo desses processos. Para tanto, optou-se pelo recurso de documentos do Google Docs que, além da funcionalidade de compartilhamento oferece a possibilidade de interação do professor através dos comentários, os quais permitem encaminhar questionamentos que conduzam o aluno em um processo de reflexão e tomada de consciência. Para a coleta de dados, os participantes utilizam as ferramentas de busca da internet e, se assim o desejarem, os participantes podem expor seus projetos através de sites de compartilhamento de projetos maker, tais como Thingverse ou Instructables.

\section{O Uso do Pensamento Formal Através da APAME}

Como foi visto, o pensamento formal, é fruto do surgimento de estruturas cognitiva que permitem ao sujeito operar sobre abstrações e hipóteses. Assim, as atividades realizadas durante o desenvolvimento de um projeto de fabricação digital devem ser orientadas no sentido de explorar possibilidades, porque essas são construídas sobre raciocínios hipotéticos, e de promover a reflexão, que é o componente principal do processo de abstração reflexionante. Cada momento da APAME pode explorar, por diferentes meios, o uso do pensamento formal, como segue:

1. Perguntar: é aquele momento em que podemos trabalhar a elaboração de hipóteses. Quando o sujeito pergunta, por exemplo, como um barco a vela se movimenta ele, internamente, começa a elaborar uma série de hipóteses. $\mathrm{O}$ sujeito poderia dizer que o barco se movimenta graças ao vento batendo na vela, ou que a movimentação se dá pela combinação do vento e das correntes, ou ainda que o movimento ocorre em função do casco do barco e do formato da vela. A necessidade de verificar essas possibilidades é que faz com que o sujeito queira conhecer, em detalhes, o objeto da sua curiosidade ou dúvida.

2. Conhecer é também o momento de realizar abstrações. Para testar a hipótese de que um barco a vela se movimenta graças ao vento batendo na vela, é preciso conhecer o vento e a vela. Ao fazer isso, o sujeito vai identificar propriedades por abstração empírica: a vela tem formatos diferentes, é fabricada com algum tipo de tecido e tem pesos diferentes quando seca e quando molhada, por exemplo. Através da abstração pseudo-empírica, o sujeito vai chegar à conclusão de que o vento tem sentido e que isso, depois de refletir, tem relação com o ângulo de incidência do vento sobre a vela. Assim é que, por abstração reflexionante, o sujeito passa a compreender a influência do ângulo de incidência do vento sobre a vela, no conjunto de forças que fazem o barco se movimentar.

3. Compreender: é aquele momento em que os porquês podem ser explorados. Não aqueles que estão relacionados a fenômenos ou acontecimentos ocorridos ao acaso e que são típicos das crianças (CORREA; ROSINEIRI, 2015), mas sim aqueles que significam "finalidade ("por que você vai por este caminho?") ou causa eficiente ("por que os corpos caem?")" (PIAGET, 1989, p. 30) e que são próprios dos adultos. Correa e Rosineiri (2015) explicam que a causa eficiente "é aquela que, por sua ação física, produz o efeito. Constitui o motivo da mudança ou transformação de um objeto." (p. 293). Dessa forma, é que perguntas como "porque o barco fica mais rápido ou mais lento quando 
VII Congresso Brasileiro de Informática na Educação (CBIE 2018)

Anais do XXIX Simpósio Brasileiro de Informática na Educação (SBIE 2018)

a direção do vento munda?" ou "como é possível que um barco veleje contra o vento?", levam o sujeito à compreensão de que a direção do vento faz com que esse incida sobre a vela em um determinado ângulo gerando uma força. Essa, por sua vez, irá se combinar com a força de resistência (da água sobre o casco) gerando uma força resultante, que não é visível, mas que pode ser identificada através da observação da velocidade do barco. Entretanto, pode acontecer de que, para chegar à essa compreensão, o sujeito necessite conhecer melhor o vento, e suas propriedades.

4. Criar é o momento quando os artefatos que irão auxiliar na comprovação das hipóteses serão fabricados. Isso envolve manipular materiais e ferramentas que, às vezes, requerem métodos específicos. Assim é que o criar pode fazer com que seja necessário conhecer e compreender esses materiais e ferramentas. Isso fará com que o sujeito desenvolva esquemas cognitivos novos, associados ao domínio da fabricação de objetos como, por exemplo, esquemas de procedimento, tais como alinhamento ou agrupamento de objetos através de um software de modelagem 3D. Além disso, a etapa de criação irá demandar dos sujeitos o uso de mecanismos metacognitivos que lhes auxiliem a organizar a produção, selecionar recursos, identificar parceiros, estabelecer colaborações, entre outros. Nessa etapa será necessária a realização de operações típicas do pensamento formal como, quando por exemplo, é preciso ajustar a combinação entre velocidade e potência do laser para se obter o efeito desejado sobre uma chapa de MDF. Ou, utilizando o raciocínio sobre proporções, o sujeito consegue desenvolver um modelo físico em escala.

5. Testar: é o momento que irá comprovar ou negar as hipóteses, ou iniciar um novo ciclo de perguntar, conhecer, compreender, criar e testar. Isso ocorre porque o sujeito operatório formal, "é um indivíduo que reflete fora do presente e elabora teorias sobre tudo, agradando-lhe considerar o que não é atual". (PIAGET, 1972, p. 190). Assim, o sujeito pode verificar que sua hipótese se confirma parcialmente ou não e, a partir disso, começar a elaborar teorias sobre o que pode ter causado o resultado observado durante o teste, considerando, inclusive, que falhas no artefato fabricado tenham sido as responsáveis. $\mathrm{O}$ sujeito pode, então, retornar à etapa de criar para fazer ajustes no artefato, ou voltar para conhecer e compreender melhor um ou mais elementos envolvidos no problema.

\section{O Uso do Pensamento Formal na Criação de Barquinhos a Vela}

A criação de barquinhos a vela foi a temática escolhida para a III Oficina de Criatividade no Contexto da Cultura Maker, a qual ocorreu ao longo de oito semanas nas dependências do POALab. Participaram alunos matriculados no $1^{\circ}$ semestre de cursos técnicos ou superior tecnológicos do IFRS, campus Porto Alegre. Partindo da pergunta "como funciona um barco a vela?", iniciamos as atividades da Oficina de Criatividade, as quais foram desenvolvidas em três ciclos da APAME:

\section{1. $1^{\circ}$ Ciclo - Criação de Barquinhos Usando Sucata}

Através da criação de barquinhos usando sucata, foi oportunizado aos participantes um primeiro contato com a temática da oficina. Esse primeiro ciclo teve a duração de quatro horas e tinha por objetivo apresentar o processo de prototipação e fazer os participantes pensarem sobre a importância das características dos materiais, os conceitos de física aplicados à vela e sobre os requisitos de design para a construção do barco. As 
VII Congresso Brasileiro de Informática na Educação (CBIE 2018)

Anais do XXIX Simpósio Brasileiro de Informática na Educação (SBIE 2018)

atividades começaram com as duplas desenhando os barquinhos que pretendiam construir. A Figura 2 mostra o desenho de Marcus e Paulo, e através dele pode-se observar que os sujeitos foram capazes de representar o barco a partir de diferentes pontos de vista, de usar a perspectiva, de pensar em detalhes como leme, porão de carga e velas, e de identificar os materiais cujas propriedades os tornavam próprios para a criação do barco, demonstrando o uso de abstração, tanto empírica como reflexionante.

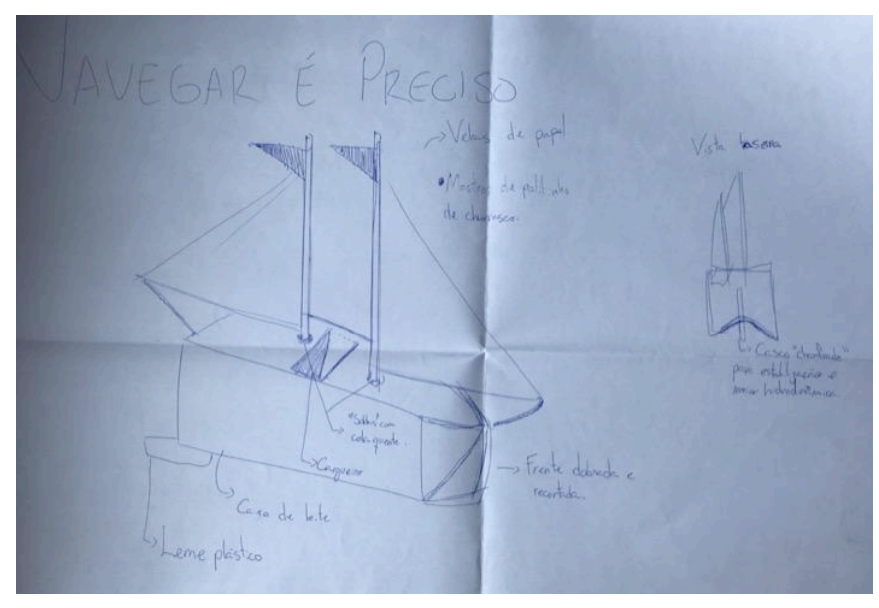

\section{Figura 2 - Desenho do barco projetado por Marcus e Paulo}

Após a etapa de desenho, os participantes, trabalhando em duplas, construíram barquinhos usando materiais provenientes de reciclagem. Inicialmente a construção se deu de forma empírica, cada dupla criando o seu barco a partir dos conhecimentos prévios que possuíam e com a única preocupação de que ele flutuasse. Para testar os barquinhos os sujeitos tinham a sua disposição uma calha plástica com água e um ventilador.

Nos primeiros testes, os sujeitos começaram a se preocupar com o material que estava sendo utilizado. Assim, ao conhecerem melhor as propriedades de cada material, passaram a compreender o impacto que esses tinham na flutuabilidade do barco. Além disso, demonstraram entender a importância da forma do casco e do projeto das velas no desempenho do barco. Sobre isso, Marcus registrou em seu portfólio: "Escolhemos fazer um barco com duas velas para que ficasse o mais parecido com um barco a vela real, depois percebemos que as velas não são apenas um artigo decorativo, mas que também influenciam muito no trajeto do barco".

Assim, vários barquinhos precisaram ser modificados. Depois de corrigidos os problemas, os barquinhos passaram por novos testes, dessa vez, para avaliar o desempenho em relação à velocidade. Nesse momento, Paulo e Marcus perceberam a importância de colocar uma quilha no barco para ajudar no direcionamento do barco evitando, assim, que ele ficasse batendo nas bordas da calha e, com isso, perdesse velocidade.

\section{2. $2^{\circ}$ Ciclo - Fabricação Digital}

Esse ciclo tinha por objetivo familiarizar os sujeitos com os equipamentos de fabricação digital (plotter de recorte, cortadora laser e impressora 3D). Na etapa de conhecer, os participantes observaram demonstrações de uso dos equipamentos e ficaram sabendo sobre o que cada máquina poderia fabricar, suas limitações e cuidados de segurança. Para compreenderem o processo de criação usando as máquinas, após receberem instruções básicas sobre como operar cada uma, os sujeitos foram convidados a criarem coisas, de preferência, relativas à temática da oficina. É importante destacar que as 
VII Congresso Brasileiro de Informática na Educação (CBIE 2018)

Anais do XXIX Simpósio Brasileiro de Informática na Educação (SBIE 2018)

peças geradas com defeito faziam com que os sujeitos voltassem às modelagens dos objetos ou às possibilidades de configurações dos equipamentos para tentar corrigir ou melhorar suas criações. Sobre o uso da cortadora laser e da impressora 3D, foram registradas questões nos portfólios para que os participantes refletissem e respondessem.

Por exemplo, sobre o corte a laser foi perguntado: "Qual a relação da distância do laser até a peça, com o resultado do corte?". Em geral, os sujeitos conseguiram estabelecer uma relação causa-consequência, que é a base de um raciocínio hipotéticodedutivo, relacionando a distância do laser com a precisão (Marcus - "a uma maior distancia haverá deformação no corte já que não será tão preciso"); com a qualidade (Paulo - "Quanto mais distante, menos foco terá o laser e mais "bruto" será o corte") e com o efeito aplicado sobre a peça (Pamela - "ele irá só desenhar ao invés de cortar").

\section{3. $3^{\circ}$ Ciclo - Fabricação de Barquinhos a Vela Usando Ferramentas Digitais}

Durante as últimas quatro semanas, os participantes ficaram livres para criar seus barquinhos. No primeiro desses quatro encontros um velejador foi convidado para dar uma rápida palestra e esclarecer dúvidas gerais que os participantes pudessem ter. Ao final do encontro, o palestrante fez uma apreciação sobre os barquinhos criados com sucata, apontando melhorias que poderiam ser feitas na construção do segundo protótipo. Nesse mesmo dia foi solicitado aos participantes que desenhassem os barquinhos que pretendiam criar. A Figura 3 mostra o projeto de Pedro e, posteriormente, chamou-nos a atenção o fato de que o barquinho que fora modelado (Figura 4) seguia o desenho do projeto, demostrando a capacidade de antecipação do sujeito, a qual é característica do estágio formal.

Chamou a atenção, também, o formato de barco escolhido por Paulo. Quando questionado sobre essa escolha ele justificou dizendo que: "A forma de trimaran foi pensada para dar uma maior estabilidade no barco, haja visto que a quilha não pode ser muito grande (devido à profundidade da calha de teste)". Identifica-se na resposta de Paulo um raciocínio lógico baseado na hipótese de que, em função da pouca profundidade do canal onde o barco iria passar, o aumento no número de cascos poderia compensar a pouca estabilidade oferecida por uma quilha de pequenas dimensões.

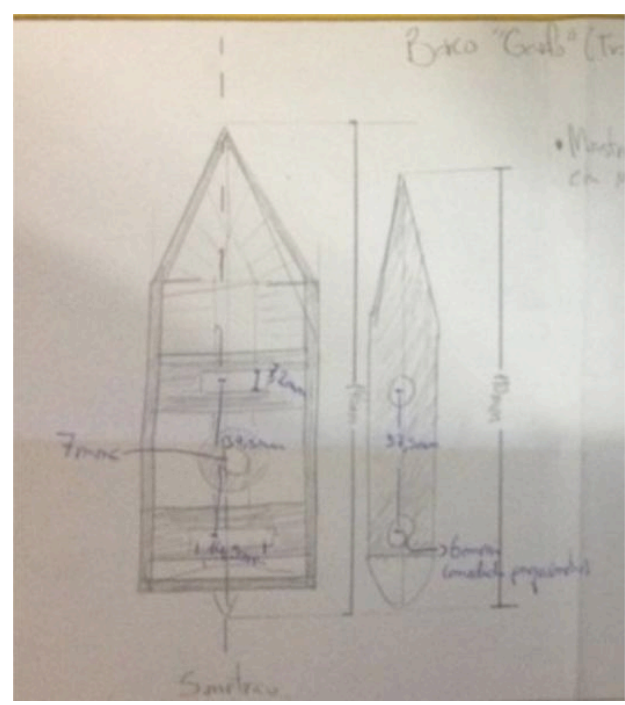

Figura 3 - Projeto do barquinho de Paulo

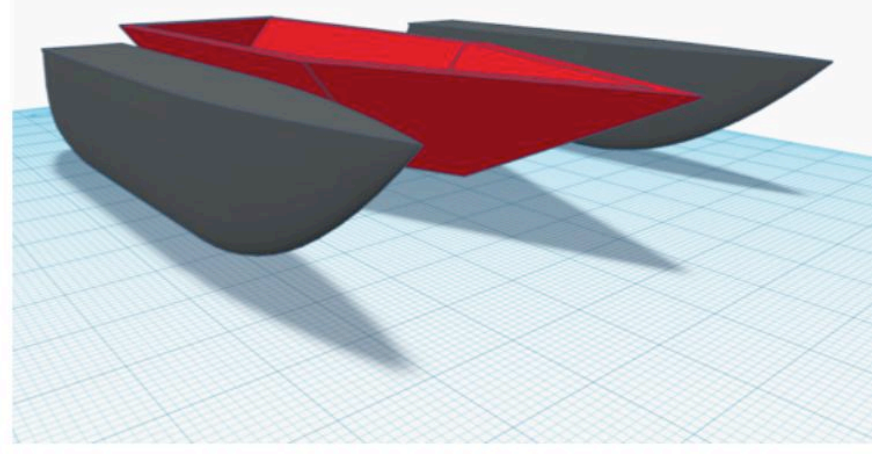

Figura 4 - Modelo 3D criado a partir do desenho 


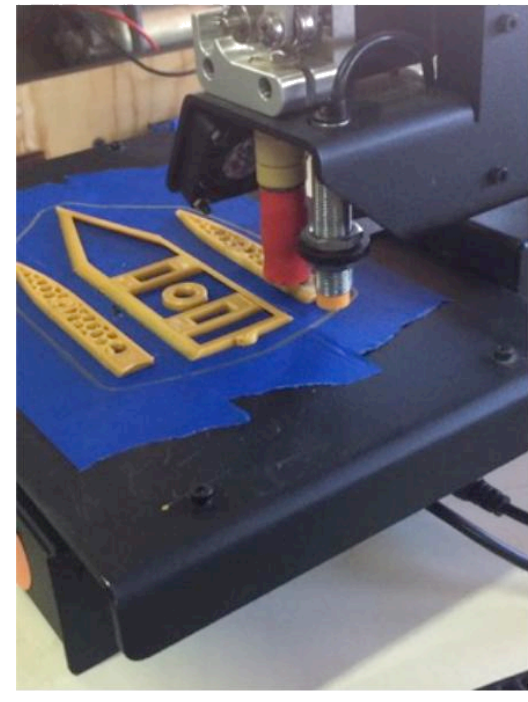

Figura 5 - Impressão em 3D do barquinho de Paulo

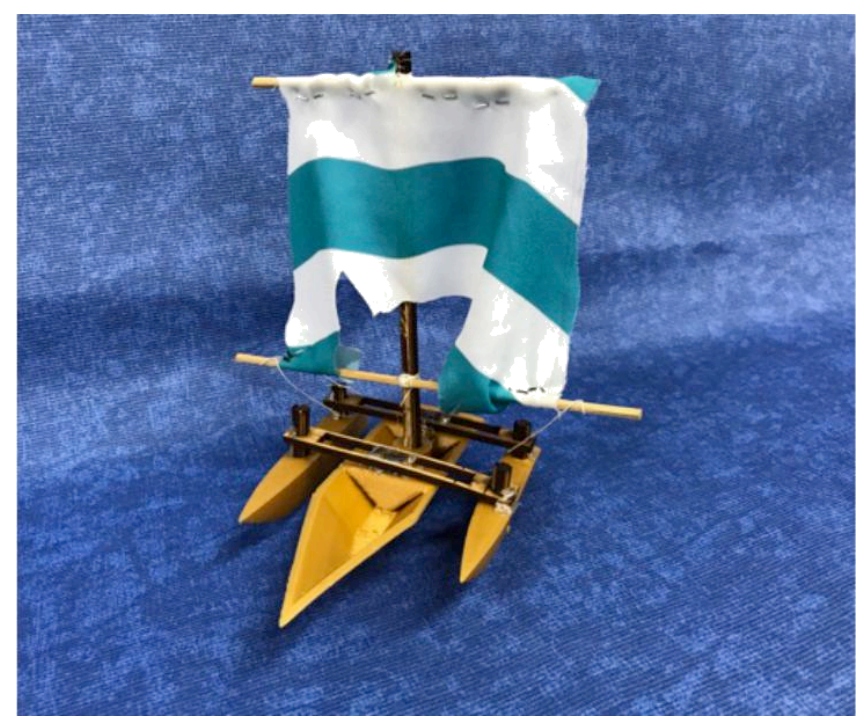

Figura 6 - Barquinho criado por Paulo

Paulo registrou em seu portfólio a imagem dos cascos sendo impressos (Figura 5) e sobre ela, ele escreveu: "Os cuidados que tomei na impressão foram o de imprimir ele de cabeça para baixo, para otimizar a impressão, gastando menos PLA para a base, e usando preenchimento de $15 \%$, para que ele fique mais leve e também mais rápido de ser impresso." Identifica-se em sua resposta a capacidade em estabelecer correlações, ou seja, a interdependência entre duas ou mais variáveis, as quais, nesse caso, são: porcentagem de preenchimento de PLA, quantidade de material, tempo de impressão e peso da peça plástica. Segundo Inhelder e Piaget (1976) a correlação só é possível porque o sujeito já consegue operar sobre proporções e combinatórias. A Figura 6 mostra o barquinho de Paulo pronto.

$\mathrm{Na}$ oitava semana realizou-se o teste final de desempenho e velocidade dos barquinhos, conforme a prática adotada durante a atividade com os barquinhos de sucata. Ao final do encontro foi postado nos portfólios um novo conjunto de perguntas sobre as quais os participantes deveriam refletir. Questionou-se, por exemplo, se seria possível que um barco navegasse em uma velocidade maior do que a velocidade do vento; o que poderia influenciar na direção de uma barco a vela à deriva; quais as rotas possíveis para um barco saindo de São Paulo em direção a Lisboa, considerando que ele teria que fazer três paradas de reabastecimento e existiriam cinco portos possíveis para atracar.

\section{Conclusões}

As atividades desenvolvidas durante a Oficina de Criatividade mostraram que a aprendizagem em makerspaces se dá, não só pela interação do sujeito com o objeto que está sendo criado, mas também pela interação com as tecnologias digitais utilizadas em sua fabricação. Seja qual for o objeto a ser fabricado, observa-se que as exigências de forma e funcionalidade impostas pelo próprio objeto são as primeiras resistências enfrentadas pelo sujeito que, ao superá-las, transforma o objeto, melhorando o seu design, e a si mesmo, na medida em que a compreensão do objeto modifica o seu sistema conceitual. Em seguida, e até mesmo concomitantemente, o sujeito se vê desafiado pelos softwares de modelagem e pelas máquinas de fabricação digital que, através das suas múltiplas possibilidades de configuração, tornam possível a concretização daquilo que antes só existia no plano abstrato.

Entretanto, tão importante quanto, ou até mais que o processo de fabricação, é a reflexão sobre o que está sendo feito e os resultados obtidos. Segundo Piaget (1978), 
VII Congresso Brasileiro de Informática na Educação (CBIE 2018)

Anais do XXIX Simpósio Brasileiro de Informática na Educação (SBIE 2018)

nesse processo a passagem da forma prática de conhecimento (fazer) para o pensamento ocorre através de tomadas de consciência, "consistindo numa conceituação propriamente dita, isto é, numa transformação dos esquemas de ação em noções e operações". (p. 10). Observou-se durante os experimentos que os sujeitos tem ritmos de trabalho diferentes, ou seja, que cada um faz as coisas a seu tempo e, consequentemente, reflete e toma consciência também em tempos diferentes. Logo, não se pode esperar que todos os sujeitos envolvidos em um projeto de fabricação digital, mesmo que o tema seja igual para todos, apresentem desenvolvimentos com a mesma qualidade.

A arquitetura pedagógica proposta é focada no sujeito epistêmico, mas não deixa de considerar o sujeito psicológico e, por isso, uma possível continuidade dessa pesquisa seria explorar a arquitetura sob o viés da psicologia analisando questões como motivação, cooperação, resiliência, iniciativa, entre outros.

\section{References}

Borges,K. S.; Menezes, C.S; Fagundes.L.C. (2017) Arquitetura Pedagógica para Aprendizagem em Makerspaces Educacionais. Revista RENOTE, v.15 n.2. Disponível em http://seer.ufrgs.br/index.php/renote/article/view/79237.

Correa, G. L.; Rosineiri, C. (2015). Os porquês da criança na psicologia genética de Piaget e na psicanálise e a dificuldade de aprendizagem. Ágora: Estudos em Teoria Psicanalítica, [s.1.], v. 18, n. 2, p. 289- 303. Disponível em http://dx.doi.org/10.1590/s1516-14982015000200009.

Inhelder, B.; Piaget, J. (1976) Da Lógica da Criança à Lógica do Adolescente: ensaio sobre a construção das estruturas operatórias formais. São Paulo: Pioneira.

Menezes, C. S. de. et al. (2006). Aplicando Arquiteturas Pedagógicas em Objetos Digitais Interativos. RENOTE - Revista Novas Tecnologias na Educação, v. 4, n. 2. Disponível em http://seer.ufrgs.br/index.php/renote/article/view/14138.

Menezes, C. S. de et al. (2013) Arquiteturas Pedagógicas Para A Aprendizagem Em Rede No Contexto Do Seminário Integrador. RENOTE - Revista Novas Tecnologias na Educação, v. 11, n. 2. Disponível em http://seer.ufrgs.br/index.php/renote/article/view/43645.

Piaget, J. (1972) A Psicologia da Inteligência. 2. ed. Rio de Janeiro: Fundo de Cultura.

Piaget, J. (1978) Fazer e Compreender. São Paulo: Melhoramentos: Ed. da Universidade de São Paulo.

Piaget, J. (1989) Seis Estudos de Psicologia. 24. ed. Rio de Janeiro: Forense Universitária.

Piaget, J. (1995) Desenvolvimento e Aprendizagem. Trad. Paulo Francisco Slomp. Porto Alegre: UFRGS/FACED/DEBAS.

Piaget, J. (1995b) Abstração reflexionante: relações lógico-aritméticas e ordem das relações espaciais. Porto Alegre: Artes Médicas.

Porvir (2018). Especial Educação Mão Na Massa. [s.d]. Disponível em http://porvir.org/especiais/maonamassa. 